\title{
Continuous Assessment as a Good Motivational Tool in Medical Education
}

\author{
${ }^{1}$ College of Medicine, University of \\ Dammam, Dammam, Saudi Arabia \\ ${ }^{2}$ University of Karachi, Karachi, Pakistan
}

Muhammad Tariq Aftab ${ }^{1}$, Muhammad Hassan Tariq ${ }^{2}$
Received: 28 September 2017
Accepted: 17 May 2018

Objective. Continuous assessment tests influence the learning needs of medical students at particular times but are also beneficial in scheduled learning, and act as motivating tool. These tests drive them to study by developing competition and optimism regarding the forthcoming result. This study has been designed to evaluate the role of these tests for medical students by learning about their motivation. Methods. This study was conducted on 150 medical students. The students selected a continuous testing system or a classical system. Those who selected the continuous system had six assessment tests each, after completion of a curriculum block, usually 45 days apart. The motivation of the students in both the groups was assessed by asking them for their expected results just before the final examination. Statistical analysis was performed using Superior Performance Statistical Software (SPSS) version 20. Results. The students' final results showed that almost half of the students who adopted the continuous assessment test system were successful and one third of those who did not adopt this system. The comparison of the successful students showed that the expectation of the students from the continuous assessment test system was high compared to the students who were not in the continuous assessment test system $(\mathrm{P}<0.05)$, even though the students in these groups had more or less similar actual marks $(\mathrm{P}>0.05)$. The comparison of the expected and actual marks of the successful students, of students who failed only one unit and of students who failed both units, showed that all these students had the same expectation $(\mathrm{P}<0.05)$ from the examination, although they had different actual marks $(\mathrm{P}>0.05)$. Conclusion. It was concluded that continuous as-

Key words: Continuous assessment tests - sessment is good for student motivation. A support system matched Medical education - Learning in medical with the individual needs of the students is suggested to improve their students - Support system.

\section{Introduction}

Medical students are the product of diverse systems and educational backgrounds, and have different hopes, standards, learning styles, adaptive skills and coping mechanisms (1). These influences and their motivation during their time at medical college have an important role in their learning, and drive them to perform in their professional examinations. Intervention in good time is important to improve the success rate and retention of at-risk students. Research in various settings has consistently shown that perception of high self-efficacy is an important positive motivational belief (2). Motivational scales are based on a broad so- 
cial-cognitive model of motivation that proposes three general motivational constructs, which are: expectancy, value and affect (3).

This study was conducted to discover student motivations, measured through their expectations after continuous and periodic tests.

\section{Methods}

This study was conducted from Jan, 2015 until March, 2016 at Karachi Medical and Dental College, after acquiring approval from the institutional ethical committee (Ref; 453/15/Ph). One hundred and fifty undergraduate medical students were included who were enrolled in the pharmacology course as a requisite of the 3rd year MBBS curriculum of the Pakistan Medical and Dental Council. The study was explained to the students and consent was obtained by $\mathrm{e}$ mail, using the official ID of the investigator. Ninety-five students adopted the continuous assessment test system, while fifty five students did not adopt this system. All students attended lectures at the same faculty, followed the same syllabus, and were taught under the same conditions. Students who adopted the continuous assessment test system took six tests, each of which was forty-five days after the previous test, upon completion of a certain stage of teaching and training, over nine months, and the result of each test was published within one week. Only students were allowed to sit the final examination who had attended $75 \%$ or more teaching sessions, and who had taken any four of the six tests throughout the term, in the case of those students who adopted the continuous assessment test system.

The final examination contained two sections, one for assessment of theoretical knowledge and the other for examining the students' practical knowledge. Each student was asked to write his expected marks on a paper just before the examination. These marks were kept confidential. Access to them was provided to the investigator after the final result.

The students were divided into three groups on the basis of their official results. The first group consisted of students who had passed the examination and attained equal to or more than $50 \%$ of marks in both sections. The second group comprised those students who failed one section and they all attained less than $50 \%$ of the marks from one of the sections, and the third group comprised those students who failed both sections and attained less than $50 \%$ of the marks from both sections separately.

\section{Statistical analysis}

We present the individual responses in tables. Distribution of the continuous variables was expressed as the mean and standard deviation, and compared by Fisher's exact test. Statistical significance was confirmed at $\mathrm{P}<0.05$. We used the statistical analysis software package SPSS 20 (SPSS Inc., Chicago, Illinois, USA) for data processing.

\section{Results}

Among the total of 150 students, 95 (63.3\%) adopted the continuous assessment test system while $55(36.6 \%)$ did not participate in this system. The students' final results show that $53(55.7 \%)$ from the group of students who adopted the continuous assessment test system and 19 (34.5\%) from the group of who did not adopt this system, passed the examination.

The mean of the expected marks of the successful students in the continuous assessment test system was 62.9 and of the students who were not in the continuous assessment test system it was 48.1. The difference is statistically significant $(\mathrm{P}<0.05)$. The mean of the actual marks of the successful students in the continuous assessment test 
Table 1. Comparison of expected and actual marks of the successful students in the two groups

\begin{tabular}{llllll}
\hline \multirow{2}{*}{ Type of marks } & \multicolumn{2}{l}{$\begin{array}{l}\text { Students in the continuous assessment test } \\
\text { system }\end{array}$} & \multicolumn{2}{l}{$\begin{array}{l}\text { Students not in the continuous assessment } \\
\text { test system }\end{array}$} & $\mathrm{P}^{*}$ \\
\cline { 2 - 5 } & $\mathrm{N}$ & Mean \pm SD & $\mathrm{N}$ & Mean $\pm \mathrm{SD}$ & 0.021 \\
\hline Expected & 53 & $62.9 \pm 06.8$ & 53 & $48.1 \pm 08.1$ & 0.237 \\
Actual & 19 & $63.7 \pm 05.5$ & 19 & $61.1 \pm 06.5$ & 0.5 \\
\hline
\end{tabular}

*Fisher's exact test.

Table 2. Differences between the actual and expected marks of the different groups of students.

\begin{tabular}{lllll}
\hline Group & Students $(\mathrm{N})$ & Marks obtained (\%)* & Expected marks (\%)* & Difference \\
\hline Pass & 53 & 63.7 & 62.9 & 00.7 \\
Failed one section & 22 & 46.2 & 55.1 & 08.9 \\
Failed both section & 20 & 34.4 & 53.5 & 19.1 \\
\hline
\end{tabular}

*Mean of \% marks.

system was 63.7 and of the students who were not in the continuous assessment test system it was 61.1. The difference is not statistically significant $(\mathrm{P}>0.05)$ (Table 1$)$.

Comparison of the two shows that the expectation of the students in the continuous assessment test system was quite high as compared to the students who were not in the continuous assessment test system, even though students from both groups had more or less similar actual marks. The difference between the actual and the expected marks of the different groups of students increases as failure occurs. It was 00.7 for successful students, 08.9 for students who failed one section, and 19.1 for students who failed both sections (Table 2).

\section{Discussion}

Medical schools prepare professionals who take on important responsibilities in human society. These schools increasingly want to understand better why some students have difficulty passing medical courses. These studies can offer medical schools an indepth insight into how they might positively influence overall student performance (3-5). We considered the role of continuous assessment tests in this regard. Although these tests influence personal learning preferences at particular times (6), they also help in the successful management of the curriculum by systematic assessment (7) and scheduled learning activities (8). We found that the group of students who adopted the continuous assessment tests system showed better results as compared to those who did not adopt this system.

A constant challenge is to motivate students entering medical college who are less well prepared for the demands of their future student life, psychologically, socially, and academically. Successful remedial and study strategy courses aimed at underprepared students have demonstrated that students who really want to improve their skills can do so when motivated (9). Placing the appropriate emphasis on testing and grading is considered to be important in the strategies, and they are needed to motivate students (10). We consider that continuous assessment tests develop competition in medical students, who are strategic learners and react well to competition. These tests are satisfying because they help develop a feeling of being in control (11) and play an important role in building their optimism (12). We, therefore, used this tool as a motivation agent in this study. 
Motivation can be assessed by expectations (13). It plays a major role in their progress by encouraging efforts to reach a target (14). We found that the group of successful students who adopted the continuous assessment tests system showed high expected marks as compared to those who did not adopt this system. The mean of the expected marks of the students in the continuous test system was significantly higher than the mean of the students in the other group, who were not in this system.

All the students in the continuous assessment test system participated in the same activities, passed through the identical teaching environment and attended tests equally, so we expected that they had more or less the same motivating influences. Perhaps this may be a reason why all the students in this group shared the same expectations for their results, as is clear from a comparison of the mean of the expected marks of the students who passed, or those who failed one section or failed both sections. Their means are not statistically different.

Although all the students in the continuous assessment test system received identical motivation and developed similar expectations, a number of students in our study could not pass the examinations. This fact leads to consideration of the factors which influence a student's performance. Some factors have an exogenous origin. The importance of resource management strategies has been reported by a number of researchers $(12,15)$. Our study did not focus on exploring these factors. The interwoven system of the structure of student needs, the teachers and their teaching abilities, and the environmental dynamics, control the factors in which they spend most their time. Throughout the world, medical educators are attempting to reform the educational environment to make it more student-friendly, without compromising the standards and quality of learning (16). The application of heutagogical principles in undergraduate medical education has not yet been studied extensively (17).

Other factors have an endogenous origin and are directly related to the student's health. Depression may be one of the causes which prevent many students from learning and performing in examinations. Roughly a third of college students report feeling depressed (18). This figure is substantially higher than in the general population (19) and appears to be increasing (20). Perhaps goals related to extrinsic values (money, image, fame) have become more important and those related to intrinsic values (selfacceptance, affiliation, community) less important nowadays, and this may also be a cause of the decline in performance (21-23).

Medical students are at high risk for depression and suicidal tendencies. In a recently published systematic review, it was estimated that $27.2 \%$ of medical students display depression or depressive symptoms, and $11.1 \%$ suicidal tendencies (24), which is a very alarming threat for medical education. Literature identifies some interventions which have been found to control this tendency (25). Friends play a significant role in mental and physical health (26). Considering all the factors of exogenous or endogenous origin, it appears that a support system must be developed in a continuous assessment test setting, which can provide help for students in coping with their deficiencies. Without this system the benefit of motivation and therefore, of the continuous system, cannot be achieved. In a study by Eccles, et al., a decline in academic performance is a reliable predictor of low self-concept, intrinsic motivation, and confidence in intellectual abilities. It is proposed by these researchers that such declines result from a developmental mismatch between early adolescents and their classroom environment, which in turn results in negative motivational outcomes, especially for struggling students (27). 


\section{Conclusion}

Our study suggests consideration by other investigators of other factors, such as fear or obligation, or a sense of responsibility, which may also have been increased by the continuous testing system, to explore the role of this system in medical students in order to optimize its benefits.

\section{What is already known on this topic}

Continuous Assessment is the educational strategy in which students are examined continuously during their study. It is a method of observing and collecting information periodically to find out what a student knows and understands. Various studies have proved the worth of this system as a tool for transmission of knowledge, and organization of academic activities, skills and abilities. However, its role in motivating students or encouraging students to acquire knowledge is perplexing, so clarification is necessary to optimize its benefits.

\section{What this study adds}

Our research broadens the understanding of the importance of the continuous test system and supports the concept that it is not merely a tool of assessment of students but also produces motivation in them to study.

Authors' contributions: Conception and design: MTA and MHT; Acquisition, analysis and interpretation of data: MHT; Drafting the article: MTA; Revising it critically for important intellectual content: MTA and MHT; Approved final version of the manuscript: MTA and MHT.

Conflict of interest: The authors declare that they have no conflict of interest.

\section{References}

1. Rehman R, Ghias K, Fatima SS, Hussain M, Alam F. Dream of a conducive learning environment: One DREEM for all medical students! J Pak Med Assoc. 2017;67(1):7-11.

2. Hauer KE, Ciccone A, Henzel TR, Katsufrakis P, Miller SH, Norcross WA, et al. Remediation of the deficiencies of physicians across the continuum from medical school to practice: a thematic review of the literature. Acad Med. 2009;84(12):1822-32.

3. Pintrich PR. A process-oriented view of student motivation and cognition. New Directions for Institutional Research. 1988;57:65-79.

4. Sandars J, Cleary T. Self-regulation theory: applications to medical education: AMEE Guide No. 58. Med Teach. 2011;33(11):875-86.
5. Mattick K, Crocker G, Bligh J. Medical student attendance at non-compulsory lectures. Adv Health Sci Educ Theory Pract. 2007;12(2):201-10.

6. Mojaddidi MA, Khoshhal KI, Habib F, Shalaby S, El-Bab ME, Al-Zalabani AH. Reassessment of the undergraduate educational environment in College of Medicine, Taibah University, Almadinah Almunawwarah, Saudi Arabia. Med Teach. 2013;35 Suppl 1:S39-46.

7. Billings-Gagliardi S, Mazor KM. Student decisions about lecture attendance: do electronic course materials matter? Acad Med. 2007;82(10 Suppl):S73-6.

8. Kelly DK. Motivating the underprepared unmotivated community college student. Viewpoints (120) - Information analyses (070). 1988; ERIC Document Reproduction Service No. ED 299009.

9. Bain K. What the Best College Teachers Do. Cambridge, Massachusetts: Harvard University Press; 2004. p. 32-42.

10. Daily Mail Reporter. How college students think they are more special than EVER: Study reveals rocketing sense of entitlement on U.S. campuses. Published 2013 [updated 2013 Jan 7; cited 2017 Feb 7]. Available from: http://www.dailymail. co.uk/news/article-2257715/Study-shows-college-students-think-theyre-special--read-writebarely-study.html\#ixzz4Xzk6AWL9.

11. Credé M, Philips LA. A meta-analytic review of the Motivated Strategies for Learning Questionnaire. Learn Individ Differ. 2011;21(4):337-46.

12. Lunenburg, FC. Expectancy Theory of Motivation: Motivating by Altering Expectations. International Journal of Management, Business and Administration. 2011;15(1):6 pages.

13. Oettingen G, Mayer D. The motivating function of thinking about the future: expectations versus fantasies. J Pers Soc Psychol. 2002;83(5):1198-212.

14. West C, Sadoski M. Do study strategies predict academic performance in medical school? Med Educ. 2011;45(7):696-703.

15. Kohli V, Dhaliwal U. Medical students' perception of the educational environment in a medical college in India: a cross-sectional study using the Dundee Ready Education Environment questionnaire. J Educ Eval Health Prof. 2013;10:5.

16. Abraham RR, Komattil R. Heutagogic approach to developing capable learners. Med Teach. 2017;39(3):295-9.

17. American College Health Association. American College Health Association-National College Health Assessment II: Reference Group Executive Summary Fall 2011. Hanover, MD: American College Health Association; 2011. 
18. Stallman HM. Psychological distress in university students: A comparison with general population data. Aust Psychol. 2010;45:249-57.

19. Twenge JM, Gentile B, DeWall CN, Ma D, Lacefield K, Schurtz DR. Birth cohort increases in psychopathology among young Americans, 1938-2007: A cross-temporal meta-analysis of the MMPI. Clin Psychol Rev. 2010;30(2):145-54.

20. Bowker JC, Spencer SV. Friendship and adjustment: a focus on mixed-grade friendships. J Youth Adolesc. 2010;39(11):1318-29.

21. Chow CM, Ruhl H, Buhrmester D. Romantic relationships and psychological distress among adolescents: Moderating role of friendship closeness. Int J Soc Psychiatry. 2015;61(7):711-20.

22. Twenge JM, Campbell WK, Freeman EC. Generational differences in young adults' life goals, concern for others, and civic orientation, 1966-2009. J Pers Soc Psychol. 2012;102(5):1045-62.

23. Rotenstein LS, Ramos MA, Torre M, Segal JB, Peluso MJ, Guille C, et al. Prevalence of Depres- sion, Depressive Symptoms, and Suicidal Ideation Among Medical Students: A Systematic Review and Meta-Analysis. JAMA. 2016;316(21):2214-36.

24. Thompson D, Goebert D, Takeshita J. A Program for Reducing Depressive Symptoms and Suicidal Ideation in Medical Students. Academic Medicine. 2010;85(10):1635-9.

25. D'Haem J. Special at school but lonely at home: an alternative friendship group for adolescents with Down syndrome. Downs Syndr Res Pract. 2008;12(2):107-11.

26. Eccles JS, Midgley C. Stage-environment fit: Developmentally appropriate classrooms for early adolescents. In: Ames R, Ames C, editors. Research on motivation in education. Vol. 3. New York: Academic Press; 1989. p. 139-81.

27. Malone K, Supri S. A critical time for medical education: the perils of competence-based reform of the curriculum. Adv Health Sci Educ Theory Pract. 2012;17(2):241-6. 